|| ISSN(online): 2589-8698 || ISSN(print): 2589-868X ||

International Journal of Medical and Biomedical Studies

Available Online at www.ijmbs.info

NLM (National Library of Medicine ID: 101738825)

Index Copernicus Value 2019: 79.34

Original Research Article

Volume 5, Issue 8; August: 2021; Page No. 46-48

\title{
CLINICAL PROFILE OF PLASMODIUM VIVAX MALARIA IN CHILDREN
}

\section{Dr Kalpesh Kumar Jain ${ }^{1}$, Dr Jasraj Bohra ${ }^{2}$}

${ }^{1}$ Junior Specialist, Department of Pediatrcs. Government Medical College Dungarpur, Rajasthan

${ }^{2}$ Junior Specialist Department of Pediatrics, Govt. Medical College, Barmer, Rajasthan

Article Info: Received 23 May 2021; Accepted 01 August 2021

DOI: https://doi.org/10.32553/ijmbs.v5i8.2070

Corresponding author: Dr Jasraj Bohra

Conflict of interest: No conflict of interest.

\section{Abstract}

Background: To study clinical presentations and complications of P. vivax malaria

Methods: A prospective hospital-based clinical observational study was conducted on 100 patients under age of 14 years were enrolled in the study.

Result: The most common presentation was fever followed by pallor. Among the total of 100 cases studied 2 cases died with a case fatality rate of $2 \%$. Among the total of 100 cases studied 5 cases (10\%) required ICU admission.

Conclusion: P. vivax monoinfection tends to have severe complications in children. There is a need to review severity criteria for P. vivax malaria.

Keywords: Vivax, Fever, ICU

\section{Introduction}

Four countries account for more than $80 \%$ of estimated cases of $P$. vivax cases (Ethiopia, India, Indonesia, and Pakistan). India alone contributes $80 \%$ of southeast Asia malaria burden. The risk of severe $P$. vivax disease in residents of endemic areas has been observed to rise with increasing transmission intensity, although the contribution of less access to care and more comorbidity in these settings is not well quantified. As a result of the slower rate of decrease in the incidence of $P$. vivax, many malaria control programs that are moving towards elimination need to give greater attention to the control of $P$. vivax, particularly in countries outside sub-Saharan Africa. Indeed, $P$. vivax predominates in countries in the preelimination and elimination phases. ${ }^{1}$

$P$. vivax malaria has long been considered to have a benign course with multiple relapses. The typical complications seen in $P$. falciparum malaria are not usually found in $P$. vivax monoinfections. However, during the past few years, the trend in the clinical manifestations of $P$. vivax malaria has been changing. Several isolated studies from India have reported severe complicated cases of $P$. vivax malaria. ${ }^{2-3}$

Although this type of malaria is an enormous burden of disease, research about the disease is scarce probably because of it being considered benign malaria compared to $P$. falciparum malaria. However, with implementation of molecular diagnosis, it has become evident that $P$. vivax monoinfection could also be involved in multiple organ dysfunction and severe life-threatening disease as seen in $P$. falciparum infection ${ }^{4}$

\section{Material and methods}

A prospective hospital-based clinical observational study was conducted on 100 patients under age of 14 years were enrolled in the study.

\section{Inclusion Criteria}

1. Children in age group of below 14 years.

2. Peripheral smear or rapid malaria antigen test (RMAT) positive for Plasmodium vivax malaria.

3. Availability of a written informed consent.

\section{Exclusion Criteria}

1. Nonavailability of consent.

2. Peripheral smear positive for $P$. falciparum or positive for both $P$. falciparum and $P$. vivax.

3. Patient presenting with fever (malarial parasite negative on peripheral smear and/or RMAT negative) but treated empirically like malaria.

\section{Diagnosis}

The diagnosis and confirmation of species of $P$. falciparum and $P$. vivax malaria were established by thick and thin film of peripheral blood smear examination under oil immersion with Giemsa stain and RDT. The RDTs were based on detection of specific Plasmodium spp. lactate dehydrogenase and histidine-rich protein.

Data Collection and Analysis 
Data regarding patient age, sex, clinical presentation, investigations, and outcome were recorded. Patients were categorized in severe and nonsevere group based on WHO guidelines for classification of severe malaria. Chi square test w11as performed to test statistical significance of sex distribution in different age buckets. Prevalence of symptoms, signs, severity criteria, lab parameters, and their relation to mortality were studied.

\section{Results}

Table 1: Demographic profile

\begin{tabular}{|l|l|}
\hline Age & $9.12 \pm 3.26$ Yrs \\
\hline Male : Female & $64: 36$ \\
\hline
\end{tabular}

Table 2: Clinical profile

\begin{tabular}{|l|l|}
\hline Fever & $96(96.00 \%)$ \\
\hline Pallor & $32(32.00 \%)$ \\
\hline Oedema & $2(2.00 \%)$ \\
\hline Body ache & $3(3.00 \%)$ \\
\hline Respiratory symptoms & $35(35.00 \%)$ \\
\hline Gastrointestinal symptoms & $37(37.00 \%)$ \\
\hline CNS symptoms & $6(6.00 \%)$ \\
\hline
\end{tabular}

Table 3: Distribution of organomegaly among total cases

\begin{tabular}{|l|l|l|}
\hline Organomegaly & Number & Percentage (\%) \\
\hline Hepatomegaly & 10 & $10.0 \%$ \\
\hline Splenomegaly & 10 & $10.0 \%$ \\
\hline Hepatosplenomegaly & 50 & $50.0 \%$ \\
\hline No hepatosplenomegaly & 30 & $30.0 \%$ \\
\hline
\end{tabular}

Among the total of 100 cases studied 2 cases died with a case fatality rate of $2 \%$. Among the total of 100 cases studied 5 cases $(10 \%)$ required ICU admission.

\section{Discussion}

Males were more affected than females, which is possibly due to increased outdoor activity and increased exposure to mosquitoes in males as compared to females. Kochar et al. found similar results in their study with $33.0 \%$ females affected among cases of $P$. vivax malaria. Age distribution among various age groups was $33.9 \%$ in $0-5$ years, $30.1 \%$ in $5-10$ years, and $30 \%$ in $>10$ years, which was almost similar in all age groups. ${ }^{6}$

A study done in East Delhi studied population of 1 to 12 years which shows $59.7 \%$ males and $40.3 \%$ females having $P$. vivax malaria, as compared to our study which shows $69 \%$ males and $31 \%$ females having $P$. vivax malaria in similar age group of 1 to 12 years $^{7}$

The most common presentation was fever, present in 96 out of total of 100 cases $(96 \%)$.
High fever trends are evident in $P$. vivax disease even with lower parasitemia due to its recognized lower feverthreshold (around 100 infected RBCs/microliter). ${ }^{8}$

It was followed by pallor which was present in 32 cases $(64.00 \%)$. Two common causes of anemia are increased hemolysis and decreased rate of erythrocyte production from bone marrow whereas the malnutrition and intestinal parasitic infections aggravate this problem in highly endemic areas. In a study about $50 \%$ of patients with $P$. falciparum and mixed infections were anemic while $29 \%$ of $P$. vivax infected cases had this abnormality ${ }^{9}$

Major confounding factors in the global analysis of anemia are the local contributors to this hematological complication such as iron-deficiency anemia ${ }^{10}$ 


\section{Conclusion}

$P$. vivax monoinfection tends to have severe complications in children. There is a need to review severity criteria for $P$. vivax malaria.

\section{References}

1. Kochar D. K., Saxena V., Singh N., Kochar S. K., Kumar S. V., Das A. Plasmodium vivax malaria. Emerging Infectious Diseases. 2005;11 (1):132-134. doi: 10.3201/eid1101.040519.

2. Sina B. Focus on Plasmodium vivax. Trends in Parasitology. 2002;18(7):287-289. doi: 10.1016/ S1471-4922(02)02329-2.

3. Picot S. Is Plasmodium vivax still a paradigm for uncomplicated malaria? Medecine et Maladies Infectieuses. 2006;36(8):406-413. doi: 10.1016 /j.medmal.2006.06.001.

4. Kochar D. K., Tanwar G. S., Khatri P. C., Kochar S. K., Sengar G. S., Gupta A., Kochar A., Middha S., Acharya J., Saxena V., Pakalapati D., Garg S., Das A. Clinical features of children hospitalized with malaria - a study from Bikaner, Northwest India. The American Journal of Tropical Medicine and Hygiene. 2010;83(5):981-989. doi: 10.4269/ ajtmh.2010.09-0633.

5. Gomber S., Kabilan L. Prevalence of malaria in East Delhi-a hospital based study. Indian Pediatrics. 1999;36(6):579-580.
6. Zimmerman P. A., Mehlotra R. K., Kasehagen L. J., Kazura J. W. Why do we need to know more about mixed Plasmodium species infections in humans? Trends in Parasitology. 2004;20(9):440447. doi: 10.1016/j.pt.2004.07.004.

7. Kochar D. K., Das A., Kochar S. K., Saxena V., Sirohi P., Garg S., Kochar A., Khatri M. P., Gupta V. Severe Plasmodium vivax malaria: a report on serial cases from Bikaner in northwestern India. American Journal of Tropical Medicine and Hygiene. 2009;80(2):194-198]

8. Lacerda M. V. G., Mourão M. P., Alexandre M. A. A., Siqueira A. M., Magalhães B. M. L., Martinez-Espinosa F. E., Santana Filho F. S., Brasil P., Ventura A. M., Tada M. S., Couto V. S., Silva A. R., Silva R. S., Alecrim M. G. Understanding the clinical spectrum of complicated Plasmodium vivax malaria: a systematic review on the contributions of the Brazilian literature. Malaria Journal. 2012;11, article 12 doi: 10.1186/1475-2875-11-12.

9. World Health Organization. WHO Guidelines for the Treatment of Malaria.2nd. Geneva, Switzerland: World Health Organization; 2010.

10. Anstey N. M., Handojo T., Pain M. C. F., et al. Lung injury in vivax malaria: pathophysiological evidence for pulmonary vascular sequestration and posttreatment alveolar-capillary inflammation. The Journal of Infectious Diseases. 2007;195(4):589596. doi: 10.1086/510756. 